\title{
Effects of Geomagnetic Dipole Variations on the Auroral Zone Locations
}

\author{
G.L. SisCoE* and L. Christopher \\ Department of Physics, Boston College, Chestnut Hill, \\ Massachusetts, U.S.A. \\ Department of Meteorology, University of California, \\ Los Angeles, California, U.S.A.
}

(Received August 18, 1975; Revised November 10, 1975)

\begin{abstract}
The purpose of this note is to point out: 1) that during geomagnetic reversals and excursion, the zones of frequent auroral occurrence will be located at very different geographical positions than at present; and 2) that two of the most recent excursions that have been suggested, the Laschamp-Gothenburg and the Lake Mungo events, are dated in upper paleolithic period (ca. 12,000 yr BP and 30,000 yr BP respectively (NöEL and TARLING, 1975; MörNER and LANSer, 1975; Barbetti and McElhinNy, 1972; Freed and Healy, 1974)), and could have produced frequent auroral displays to major populations of stone age people. The second point might be important because it opens the possibility that some of the previously uninterpreted artifacts and drawings from this period could be representations of auroral forms.
\end{abstract}

At present the aurora are seen most frequently in fairly narrow, approximately latitudinal bands around $70^{\circ}$ north and south. In these so-called auroral zones, the aurora is a nightly occurrence. The location of the auroral zones is determined by the present values of the strength and orientation of the magnetic dipole of the earth and by average solar wind parameters. Statistics of auroral occurrence at low latitudes are governed by the statistics of variations of certain solar wind parameters. We assume for this discussion that solar wind averages and statistics have remained constant in time, and look at the changes in the location of the auroral zones that result from changes in the geomagnetic field that occur during reversals and excursions. In particular we concentrate in this note on the effect of decreasing the strength of the dipole, and on excursions of the dipole axis.

There is not complete agreement among paleomagnetists about whether the dipole axis actually moves much during one of these events or whether the ap-

* On leave from the Department of Meteorology, University of California, Los Angeles, California 90024, U.S.A. 
parent motion of the magnetic pole as inferred from measurements at a single site is due to the dominance of local non-dipole components. It is possible that among the many geomagnetic events that have occurred in geological time, both types of behavior can be found. Whether the dipole direction changes much or not, the dipole strength is generally believed to decrease significantly during reversals. With regard to the question of the direction of the dipole axis, we explore here the simple hypothesis that it moves as indicated by the measured "virtual pole positions." An alternative hypothesis, local dominance of nondipole components, results in more complicated effects on the distribution of auroral zones and will be considered in a separate note.

The pole position varies continuously but except during reversals and excursions the variation is mainly in longitude (DoELL and Cox, 1971; KAWAI et al., 1967; KAW AI and HirookA, 1967; BARraclough, 1974). Its latitude is confined to within $5^{\circ}$ of its average value of $79^{\circ}$, which is also the present value. The auroral zones are observed to be centered on the dipole axis rather than the rotational axis (Vestine, 1944). Changes in auroral zone positions associated with longitudinal drift of the dipole axis have been inferred from historical auroral records (Keimatsu et al., 1968). But the polar latitude of the magnetic poles has confined the auroral zones to high latitudes throughout historic times, as indicated by the historical compilation of Fritz (1881) (reproduced for example in Chapman and Bartels (1940)) and by the more recent studies of Schove (1955).

The latitude relative to the dipole equator (i.e. the great circle perpendicular to the dipole axis) of the zones is determined by the dipole strength. The geomagnetic latitude of the zones is insensitive to the angle between the dipole axis and the solar wind direction as indicated by the present $34^{\circ}$ annual oscillation in this angle $\left(23^{\circ}\right.$ from the inclination of the rotation axis to the ecliptic and $11^{\circ}$ from the dipole tilt relative to the rotation axis) and from theoretical models of "pole-on" magnetospheres (SiSCOE, 1975). The geomagnetic latitude of the auroral zones has been calculated as a function of dipole strength (SISCOE and CHEN, 1975) and the result is extended in Fig. 1 to give the (geomagnetic) latitudinal dependence of the nightly occurrence probability for three dipole strengths.

The figure shows that the auroral zones expand (decrease in latitude) and the latitudinal range of frequent auroral occurrence increases as the dipole strength decreases. For a dipole strength of 10 per cent of the present value, aurora should occur every night at geomagnetic latitude $61^{\circ}$ and at least one night in four (on average) at a geomagnetic latitude as low as $37^{\circ}$. This range in geographic latitude separates Athens and Leningrad and covers more than one quarter of the surface of the earth. 


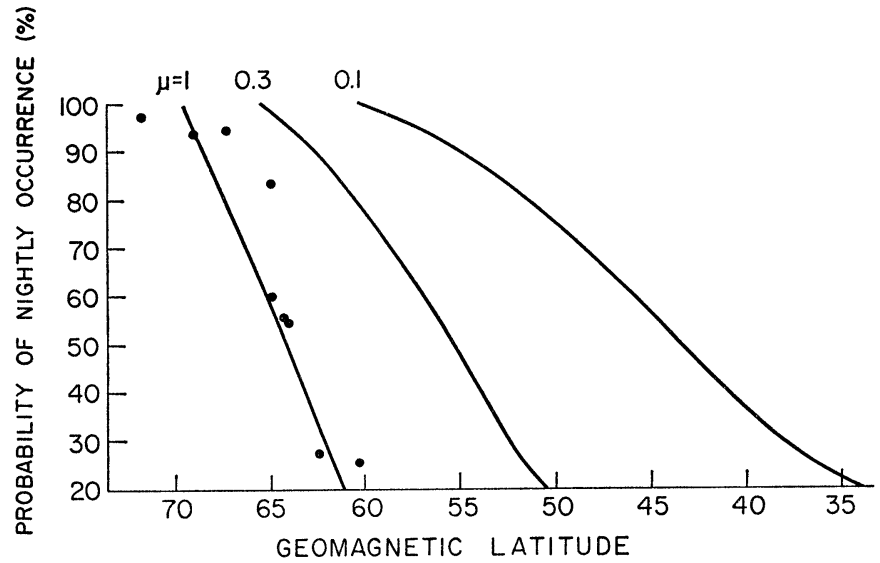

Fig. 1. The probability of aurora occurrence over any 6 hour period (identified here as the probability of nightly occurrence) as a function of geomagnetic latitude for dipole strengths $M_{E}(0), 0.3 M_{E}(0)$, and $0.1 M_{E}(0)$, where $M_{E}(0)$ is the present dipole strength $\left(\mu=M_{E} / M_{E}(0)\right)$. The curves are calculated using a NisHidA-BRICE $(1966,1967)$ model of convection modified by superimposing a uniform magnetic field on the dipole to give the proper polar cap opening. The lower latitude of the aurora is identified with the inner edge of the convection region and $1.5^{\circ}$ latitude is subtracted to account for the visual range of the aurora. Statistics on the solar wind merging electric field are obtained from six months of Mariner 5 spacecraft data. The maximum merging field observed in consecutive 6 hour intervals were used for the statistics. A merging efficiency of 20\% was assumed. See SisCOE and CHEN (1975) for further details. The data points on the $\mu=1$ curve give the observed probability at different stations (BOND and JACKA, 1962).

The above discussion suggests a helpful mental image for considering what happens to the aurora during geomagnetic reversals and excursion. Picture two cones with their apexes at the earth's center and their axes parallel to the dipole axis. One cone opens in the direction of the + polar axis and the other opens in the opposite direction. The cones can be thought of as the beams of back-toback flashlights located at the earth's center and pointing along the dipole axis. The intersection of these cones ("flashlight beams") with the ionosphere is the auroral zone. The opening angle of the cones increases with decreasing dipole strength, as shown in Fig. 1. Also, if the direction of the dipole changes, the cones and the auroral zones move correspondingly.

Detailed studies of three major reversals identified as the upper and lower Jaramillo and the upper Olduvai show that these reversals combined virtual pole excursions with decreases in dipole strength to the order of 10 per cent of the prereversal value (OPDYKe et al., 1973). Similar detailed information does not yet exist for the much briefer recent excursions, although a decrease of approx- 
imately 85 per cent in strength has been suggested for the Laschamp event (Freed and Healy, 1974). Freed and Healy (1974) report virtual pole excursions for the two upper paleolithic events which they identify as the Laschamp and the Lake Mungo. In the more recent event, the present northern pole swept through Europe in both a southward and a subsequent northward excursion. In the older event the present southern pole crossed the equator in the meridian sector of Europe and continued as far as North Africa. HARrison and RAmirez (1975) suggest that these recent events could be geographically local, and might not represent large changes in the main dipole component. In this case our contention that the auroral zones were differently situated than they are today is still valid, but the calculation of their position would involve the presence of a large quadrupole component. The location of auroral zones in a quadrupole magnetic field will be discussed in a subsequent paper. If for the purposes of illustration we assume that the virtual pole excursions reported by Freed and Healy represent motions of the main dipole axes, we note that in both cases they would have swept the "flashlight beam" of the aurora across the European sector.

This work was supported in part by AFCRL Contract No. F19628-74-C-0015 and by the National Science Foundation under grant GA-38414 (Boston College) and GA-3182 (UCLA).

\section{REFERENCES}

Barbetti, M. and M. McElhinny, Evidence of a geomagnetic excursion 30,000 yr BP, Nature, 239, 327-330, 1972.

BarRaClough, D.R., Spherical harmonic analysis of the geomagnetic field for eight epochs between 1600 and 1910, Geophys. J. R. Astr. Soc., 36, 497-513, 1974.

BOND, F.R. and F. JACKA, Distribution of auroras in the southern hemisphere, II Nightly probability of overhead aurora, Autsr. J. Phys., 15, 261-272, 1962.

Brice, N.M., Bulk motion of the magnetosphere, J. Geophys. Res., 72, 5193-5212, 1967.

Chapman, S. and J. Bartels, Geomagnetism, p. 469, Oxford Press, 1940.

Doell, R.R. and A. Cox, Pacific geomagnetic secular variations, Science, 171, 248-254, 1971.

Freed, W.K. and N. Healy, Excursions of the Pleistocene geomagnetic field recorded in Gulf of Mexico sediments, Earth Planet. Sci. Lett., 24, 99-104, 1974.

Fritz, H., Das Polarlicht, Brockhaus, Leipzig, 1881.

HARrison, C.G.A. and E. RAMirez, Areal coverage of spurious reversals of the earth's magnetic field, J. Geomag. Geoelectr., 27, 139-151, 1975.

KAWAI, N. and K. HIROOKA, Wobbling motion of the geomagnetic dipole field in historic time during these 2000 years, J. Geomag. Geoelectr., 19, 217-227, 1967.

KaWAi, N., K. Hirooka, and K. Tokieda, A vibration of geomagnetic axis around the geographic north pole in the historic time, Earth Planet. Sci. Lett., 3, 48-50, 1967.

Keimatsu, M., N. Fukushima, and T. NAgata, Archaeo-aurora and geomagnetic secular variation in historic time, J. Geomag. Geoelectr., 20, 45-50, 1968.

Mörner, N.A. and J. LANSER, Paleomagnetism in deep-sea core A179-15, Earth Planet. Sci. Lett., 26, 121-124, 1975. 
NishidA, A., Formation of plasmapause or magnetospheric plasma knee, by the combined action of magnetospheric convection and plasma escape from the tail, J. Geophys. Res., 71, 5669-5680, 1966.

NoËL, M. and D.H. TARLING, The Laschamp geomagnetic 'event', Nature, 253, 705-707, 1975. OPDYKe, N.D., D.V. Kent, and W. LowrIE, Details of magnetic polarity transitions recorded in a high deposition rate deep-sea core, Earth Planet. Sci. Lett., 20, 315-324, 1973.

Schove, D.J., The sunspot cycle, 649 B.C. to A.D. 2000, J. Geophys. Res., 60, 127-146, 1955.

SisCOE, G.L., Particle and field environment of Uranus, Icarus, 24, 311-324, 1975.

Siscoe, G.L. and C.-K. Chen, The paleomagnetosphere, J. Geophys. Res., 80, 4675-4680, 1975.

VESTINE, E.H., The geographic incidence of aurora and magnetic disturbance, northern hemisphere, Terr. Mag. Atmos. Elect., 49, 77-102, 1944. 